\title{
Delay in diagnosis of pulmonary tuberculosis increases the risk of pulmonary cavitation in pastoralist setting of Ethiopia
}

Fentabil Getnet ${ }^{1,4^{*}}$, Meaza Demissie ${ }^{2}$, Alemayehu Worku ${ }^{2,3}$, Tesfaye Gobena ${ }^{4}$, Rea Tschopp ${ }^{5,6,7}$, Michael Girmachew ${ }^{8}$, Gebeyehu Assefa ${ }^{5}$ and Berhanu Seyoum ${ }^{5}$

\begin{abstract}
Background: Delay in diagnosis and treatment of pulmonary tuberculosis (PTB) leads to severe disease, adverse outcomes and increased transmission. Assessing the extent of delay and its effect on disease progression in TB affected settings has clinical and programmatic importance. Hence, the aim of this study was to investigate the possible effect of delay on infectiousness (cavitation and smear positivity) of patients at diagnosis in Somali pastoralist area, Ethiopia.

Methods: A cross-sectional study was conducted between December 2017 and October 2018, and 434 newly coming and confirmed PTB patients aged $\geq 15$ years were recruited in five facilities. Data were collected using interview, record-review, anthropometry, Acid-fast bacilli and chest radiography techniques. Log-binomial regression models were used to reveal the association of delay and other factors associated with cavitation and smear positivity, and ROC Curve was used to determine discriminative ability and threshold delays.

Results: Median age of patients was 30 years. Of all, $62.9 \%$ were males, and $46.5 \%$ were pastoralists. Median diagnosis delay was 49 days $(I Q R=33-70)$. Cavitation was significantly associated with diagnosis delay $[P<0.001] ; 22.2 \%$ among patients diagnosed within 30 days of illness and $51.7 \%$ if delay was over 30 days. The threshold delay that optimizes cavitation was 43 days [AUC $(95 \% \mathrm{Cl})=0.67(0.62-0.72)$ ]. Smear positivity was significantly increased in patients delayed over 49 days $[p=0.02]$. Other factors associated with cavitation were age $\leq 35$ years [APR $(95 \% \mathrm{Cl})=1.3(1.01-1.6)]$, chronic diseases $[$ APR $(95 \% \mathrm{Cl})=1.8(1.2-2.6)]$ and low MUAC *female $[$ APR $(95 \% \mathrm{Cl})=1.8(1.2-2.8)]$. Smear positivity was also associated with age $\leq 35$ years [APR $(95 \% \mathrm{Cl})=1.4(1.1-1.8)]$, low BMI [APR $(95 \% \mathrm{Cl})=1.3(1.01-1.7)$ ] and low MUAC [APR $(95 \% \mathrm{Cl})=1.5(1.2-1.9)]$.

Conclusion: This study highlights delay in diagnosis of pulmonary TB remained high and increased infectiousness of patients in pastoral settings of Ethiopia. Hence, delay should be targeted to improve patient outcomes and reduce transmission in such settings.
\end{abstract}

Keywords: Diagnosis delay, Tuberculosis, Cavitation, Smear positivity, Pastoralist, Ethiopia

\footnotetext{
* Correspondence: b.infen4ever@gmail.com

${ }^{1}$ College of Medicine and Health Sciences, Jigjiga University, Jijiga, Ethiopia

${ }^{4} \mathrm{~S} c h o o l$ of Public Health, Haramaya University, Dire Dawa, Ethiopia

Full list of author information is available at the end of the article
}

(c) The Author(s). 2019 Open Access This article is distributed under the terms of the Creative Commons Attribution 4.0 International License (http://creativecommons.org/licenses/by/4.0/), which permits unrestricted use, distribution, and reproduction in any medium, provided you give appropriate credit to the original author(s) and the source, provide a link to the Creative Commons license, and indicate if changes were made. The Creative Commons Public Domain Dedication waiver (http://creativecommons.org/publicdomain/zero/1.0/) applies to the data made available in this article, unless otherwise stated. 


\section{Background}

Tuberculosis (TB) remains the leading killer of infectious diseases. Globally, it caused an estimated 10 million cases and 1.3 million deaths in 2017. Ethiopia ranked 11th among the 22 high TB burden countries and 4th in Africa with around 172, 000 new cases in 2017 [1]. The disease is more prevalent in pastoral communities of the country [2]. The End-TB strategy sets early diagnosis and prompt treatment of cases as pillars to ending the global epidemics by 2030 [3]. Particularly in Ethiopia, the national TB control program (NTP) primarily focuses on detection of presumptive TB cases who present themselves to health facilities, aka passive case finding strategy [4].

However, this passive approach struggles to achieve the required case detection rates in resource-limited settings, leaving millions of potentially infectious cases undiagnosed in communities [5, 6]. Nearly one-third of TB cases in Ethiopia were not detected in 2017 [1]. The number of undetected cases could be equal or more than the number of cases detected by the healthcare system in certain communities of the country $[6,7]$. In Somali Regional State of Ethiopia (SRS), TB case detection rates have never exceeded $50 \%$ in the past years [8]. The problem is likely influenced by healthcare seeking behavior of patients or health system deficiencies $[9,10]$. Patients may delay without seeking healthcare, or the healthcare providers may fail to identify presented cases [11].

Delay in diagnosis and treatment leads to severe disease, death, and facilitates transmission in households and congregate settings. Fail to timely treat PTB leaves destructive damages to lung tissues, the classical hallmark is pulmonary cavitation [12, 13]. The cavities formed are caves for Mycobacterium tuberculosis (MTB) and release higher bacilli load in aerosols [14], which is the channel of transmission. Cavities also slow smear conversion (prolongs contagious period), cause adverse treatment outcomes, and leave permanent lung damages even after successful treatment [15]. Along with disease progression, delay also extends contagious period and contact time between patients and susceptible contacts [16].

This highlights assessment of delay in medical care and its impact is very helpful to evaluate the effectiveness of TB programs in controlling the disease and its transmission in affected communities. There is also limited data on the prevalence of cavitary TB and the tolerable delays from clinical and programmatic perspectives in Ethiopia. Hence, the aim of this study was to evaluate the possible effect of diagnosis delay on pulmonary cavitation and smear positivity as proxy measures of patient infectiousness in Somali Regional State of Ethiopia, a pastoralist predominated area.

\section{Methods}

\section{Study setting}

Four hospitals (Kharamara, Dege-habour, Kebri-Daher and Gode) and one health center (Abilelie) were included based on their high patient flow, presence of radiologic facility, and geographic location in Somali Regional State of Ethiopia. Approximately $85 \%$ of the region's population are rural and lead pastoral life that is characterized by seasonal migration following climatic conditions [17]. The health facilities provide TB diagnosis services as per the national guideline, which involves two spot-spot smear microscopy spaced by $30 \mathrm{~min}$ (and morning on demand), chest radiography, GeneXpert, pathology and clinical investigations [4].

\section{Study design and population}

A facility-based cross-sectional study was conducted between December 2017 and October 2018. Newly diagnosed PTB patients aged $\geq 15$ years were included regardless of smear status and treatment category. Patients aged $\geq 15$ years manifest similar pathological features and the same diagnosis approaches are followed [4]. People in this age category acquire competent immunity that is key in cavity formation [18], cover $80 \%$ of all TB cases, and account for almost 100\% of transmissions [19]. Patients with other pulmonary co-morbidities (bronchitis, pneumonia and lung cyst) were excluded.

\section{Sample size and sampling technique}

The minimum sample size estimated was 282 using OpenEpi303 software for cross-sectional studies. The assumptions were $95 \% \mathrm{CI}, 80 \%$ power, 1:1 ratio of nondelayed/delayed, $27.5 \%$ of non-delayed and $45 \%$ of delayed patients had cavitation in related study [12], 5\% precision and $10 \%$ non-response rate, given delay above 30 days as critical point at which risk of transmission increases [20]. We included all the available samples in the analysis to increase the power of the test, which raised the final sample size to 434 . Newly upcoming PTB patients during the study period were recruited immediately after diagnosis and before treatment initiation.

\section{Data collection}

A mix of methods was used to collect data including face-to-face interview, record review, anthropometry, Acid-Fast Bacilli (AFB) and chest radiography. Interviews were conducted using a structured questionnaire (translated into native Somali and Amharic languages), questions were adapted from multinational study in Eastern Mediterranean WHO region [21] and related studies in Ethiopia [11, 22, 23]. Records were reviewed to substantiate co-morbidities and medical history. Anthropometry measurements were also taken. Upon completion of interviews and anthropometry, patients were 
linked to laboratory and radiology units using request forms prepared for this purpose. Nurses working in DOTS clinics carried out recruitment, interview, record review and anthropometry procedures. Training was provided on sampling and data collection procedures by the principal investigator and a local research assistant.

\section{AFB examination}

Three sputum specimens from each patient were collected; morning sputum at home, and two spot specimens spaced by $30 \mathrm{~min}$ after the patient delivered the morning specimen. A pair of smears was prepared from each specimen, air dried and heat fixed. One slide of each pair was examined at hospital laboratories using Ziehl Neelsen (ZN) staining technique. The rest three smears were transported and examined blindly at Armauer Hansen Research Institute (AHRI) TB laboratory in Addis Ababa, Ethiopia (Fig. 1). The results were interpreted as negative (no AFB), scanty (1-9 AFB/100 field), 1+ (10-99 AFB/100 field), 2+ (1-10 AFB/field), $3+(>10 \mathrm{AFB} /$ field $)[4]$.

\section{Chest radiography}

All patients were set for Chest X-ray examinations to identify lung cavitation, measure cavity size and count the number of cavities. A senior radiologist at Kharamara hospital examined all the X-ray films and digital images. The radiologist was blinded to radiologic and AFB results reported during the standard initial diagnosis. Sample of X-ray films $(n=41)$ were randomly picked and blindly rechecked by another radiologist to ensure the reliability of $\mathrm{X}$-ray readings. As of rechecking, we found levels of $95.1 \%$ [84.6-100\%] kappa agreement for cavity identification, $0.84[0.64,0.93]$ Cohen's kappa coefficient for cavity size, and $85.7 \%$ [63.7-96.9\%] Cohen's proportion of zero difference for cavity count.

\section{Measurements \\ Pulmonary cavitation}

Is presence of an air-containing lucent space within a consolidation or a mass or nodule surrounded by infiltrate or fibrotic wall identified upon radiological examination $[18,24]$

\section{Smear positivity}

Was confirmed if at least one sputum smear was positive for AFB upon rechecking at hospital and TB research laboratories [4]

\section{Diagnosis delay}

Is the time duration from onset of pulmonary symptoms to date of diagnosis. Patients were asked the first dates of illness onset, healthcare provider consultation, and diagnosis. If patients were unsure of the dates, they were assisted to associate with main religious or cultural events. Patient cards were also cross-checked. Then the interval between illness onset and diagnosis was calculated. Cough was the benchmark of illness onset, but another symptom that compelled the patients to seek care was also used in the absence of cough.

\section{Mid-upper arm circumference (MUAC)}

Was measured using inelastic paper tapes and categorized at $23 \mathrm{~cm}$ cutoff (low if MUAC $\leq 23$ ) according to FANTA's recommended cutoff to assess undernutrition in adults [25]

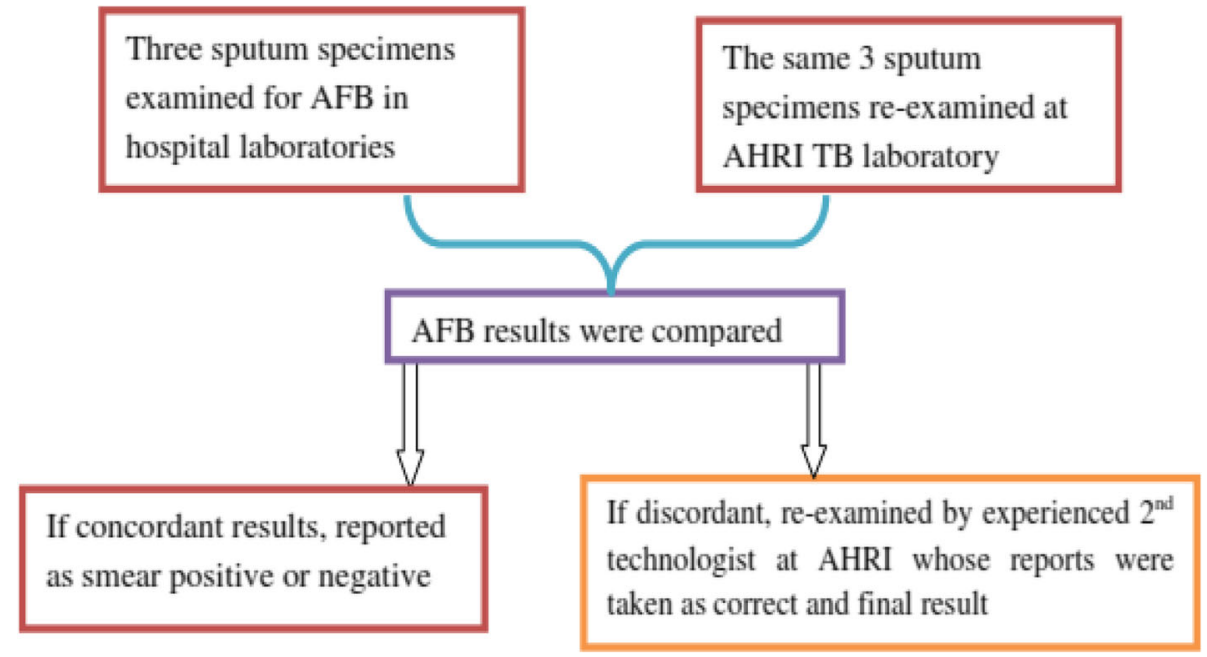

Fig. 1 AFB examination algorithm at hospital and research laboratories 


\section{Body mass index (BMI)}

Was computed from weight (kilograms) and height (meter-square) measures, and categorized at $18.5 \mathrm{Kg} / \mathrm{M}^{2}$ cutoff (low if BMI < 18.5) according to FANTA's recommended Cutoff to assess undernutrition in Adults [25].

\section{Data processing and analysis}

Data were double entered and validated using EpiData version 3.1; and analyzed using Stata version 14 (StataCorp, College Station, Texas 77,845 USA). Descriptive statistics was done to summarize delays in diagnosis, cavitation, smear positivity and explanatory variables. Since cavitation and smear positivity were common outcomes (>10\%), prevalence ratios with $95 \%$ confidence intervals $(\mathrm{CI})$ were used to reveal the association of delay and other factors associated with cavitation and smear positivity. Two log-binomial regression models were fitted using cavitation and smear positivity as separate outcomes of interest. Significance was determined at $p \leq$ 0.05 , and variables with $p \leq 0.2$ in bivariate analyses were included in final multivariable models. Receiver Operating Characteristic (ROC) curve was used to determine the discriminative ability of delay to predict patients with cavitation and smear positivity. Threshold delays were determined at given sensitivity $(>70 \%)$ and maximum positive likelihood ratio.

\section{Results}

\section{Patient characteristics}

Totally, 434 pulmonary TB patients were included; all and 421 of them had complete chest radiography and AFB results, respectively. The median age of participants was 30 years, ranged 15 to 82 years. The majority (62.9\%1) was male, and close to half (46.5\%) were reliant on pastoralism (of which, 36\% nomadic). Regarding clinical characteristics, majorities were new cases (90.3\%), and $2.3 \%$ were co-infected with HIV (Table 1).

The median diagnosis delay from onset of illness to the date of TB diagnosis was 49 days $(\mathrm{IQR}=33-70)$, ranged 8 to 362 days. Four patients had diagnosis delay greater than 254 days.

\section{Patient infectiousness (cavitation and smear positivity)}

Of the 434 PTB cases, 45.6\% [95\%CI: 40.9-50.4\%] had single-to-five cavities (mean, $1.8 \pm 0.9$ cavities) with mean diameter of $2.8 \pm 1.0 \mathrm{~cm}$. Of the non-cavitary cases, $5.5 \%$ had consolidated lesions but not duly branded as cavity. Whereas, 42.0\% [95\%CI: 37.3-46.9\%] of patients were smear positive upon rechecking. In hospital laboratories, $19.2 \%$ of smear positive patients were misidentified as smear negative and $2.9 \%$ of smear negative as smear positive. Smear positivity was multifold among cavitary patients $(75.3 \%)$ compared with non-cavitary counterparts (13.7\%), $[P<0.001]$. Conversely, cavitation was $82.5 \%$ [95\%CI: 76.1-87.8\%] among smear positive patients. AFB examination correctly identified $75.3 \%$ [95\%CI: $68.6 \quad 81.2 \%$ ] of patients with cavitation (sensitivity) and $86.3 \%$ [95\%CI: 81.2-90.5\%] without cavitation (specificity) (Table 2).

\section{Delay and other factors associated with patient infectiousness}

Cavitation was significantly associated with diagnosis delay $[p<0.001]$. When categorized at 25th, 50th and 75th percentiles, cavitation was continually increased among patients with diagnosis delay of 31-49 days [APR $(95 \% \mathrm{CI})=1.8(1.2-2.8)], 50-70$ days $[\mathrm{APR}(95 \% \mathrm{CI})=2.4$ $(1.6-3.7)]$ and $71+$ days $[$ APR $(95 \% \mathrm{CI})=2.7(1.8-4.1)]$, given diagnosis delay $\leq 30$ days as reference. Ninety percent $(90 \%)$ of cavitary patients had delay above 30 days (Table 3). Smear positivity was also significantly increased among patients with diagnosis delay above 49 days $[$ APR $(95 \% C I)=1.3(1.1-1.6), p=0.02$ ] (Table 4).

Other factors associated with cavitation were age $\leq 35$ years $[\mathrm{APR}(95 \% \mathrm{CI})=1.3(1.01-1.6)]$, chronic diseases (Hypertension/chronic Heart/Renal Disease) [APR $(95 \% \mathrm{CI})=1.8(1.2-2.6)$ ], and low MUAC (in female only) [APR $(95 \%$ CI $)=1.8(1.2-2.8)]$ (Table 3). Similarly, smear positivity was associated with age $\leq 35$ years [APR $(95 \% \mathrm{CI})=1.4(1.1-1.8)]$, low BMI [APR $(95 \% \mathrm{CI})=1.3$ $(1.01-1.7)]$, and low MUAC [APR $(95 \% \mathrm{CI})=1.5(1.2-$ 1.9)] (Table 4).

\section{Discriminative ability of delay to predict cavitation and smear positivity}

The ROC curve shows that diagnosis delay discriminated pulmonary cavitation, and the area under the ROC curve (AUC) was 0.67 [95\%CI: 0.62-0.72]. The threshold delay was determined at 43 days, at which the resulting sensitivity, specificity and the likelihood ratio for positive test result were $74.6,52.1 \%$ and 1.6 , respectively (Fig. 2). At this cutoff point, delay can correctly classify $62.4 \%$ of patients with or without cavitation, and $60.0 \%$ of patients delayed longer than 43 days without obtaining diagnosis. Nonetheless, diagnosis delay revealed poor discriminative ability to predict smear positivity [AUC (95\% CI): 0.56 (0.51-0.62)] (Fig. 3).

\section{Discussion}

The present finding reveals that close to half (45.6\%) of all and $82.5 \%$ of smear positive patients with pulmonary TB had one or more cavities; $42 \%$ were smear positive, and half of patients delayed more than 7 weeks (49 days) and few nearly a year without medical care. Cavitation was increased in patients who delayed longer than 30 days and optimized at threshold delay of 43 days. Similarly, smear positivity was increased in patients who delayed above 7 weeks. 
Table 1 Socio-demographic and clinical characteristics of TB patients in Somali region, Ethiopia, December 2017 to October 2018

\begin{tabular}{ll}
\hline Characteristics of patients $(N=434)$ & Frequency (\%) \\
\hline Sex & \\
Male & $273(62.9)$ \\
Female & $161(37.1)$
\end{tabular}

Age group

15 to 23

24 to 30

31 to 50

$51+$

Literacy level

|lliterate

Primary

Secondary

Tertiary

Marital status

Single

Married

Divorced/separated/widowed

Residence

Rural

Urban

Refugee/displaced

Livelihood

Pastoralism

Other

Income

Saving
Income= expense
Indebt
Cough
Yes
No

Haemoptysis

Yes

No

Chest pain

Yes

No

Breathing difficulty

Yes

No

Functional status

Good

Ambulatory

202 (46.5)

$232(53.5)$

54(12.5)

303 (69.8)

$77(17.7)$

$412(94.9)$

$22(5.1)$

$33(7.6)$

$401(92.4)$

250 (57.6)

$184(42.4)$

$93(21.4)$

341 (78.6)

$60(13.8)$

$360(83.0)$
Table 1 Socio-demographic and clinical characteristics of TB patients in Somali region, Ethiopia, December 2017 to October 2018 (Continued)

\begin{tabular}{ll}
\hline Characteristics of patients $(N=434)$ & Frequency (\%) \\
\hline Bedridden & $14(3.2)$ \\
Treatment category & $392(90.3)$ \\
New & $42(9.7)$ \\
Retreatment & \\
History of tuberculosis & $65(15.0)$ \\
Yes & $369(85.0)$ \\
No & \\
HIV status & $10(2.3)$ \\
Positive & $422(97.2)$ \\
Negative & $2(0.5)$ \\
Unknown & \\
Diabetes mellitus & $16(3.7)$ \\
Yes & $412(94.9)$ \\
No & $6(1.4)$ \\
Unknown & \\
Smoking history & $45(10.4)$ \\
Ever smoker & $389(89.6)$ \\
Never smokers & \\
Khat chewing & $58(13.4)$ \\
Ever chewer & $376(86.6)$ \\
\hline Never chewer &
\end{tabular}

Cavitation and smear positivity were reciprocally illustrative, and about half of patients had intricate form of the disease and were capable of transmitting TB. The cavitation rate matches with the maximum assumption of $50 \%$ rate that happens if patients do not receive treatment during the entire course of the disease [26, 27]. It surpassed $34.0 \%$ [28] and 21\% [29] findings reported elsewhere. Cavitation among smear positive patients was almost twice to previous reports of $49.9 \%$ [29] and $38.3 \%$ [30] in other places. Nonetheless, smear positivity was comparable to other reports in Ethiopia [31-33]. This implies that many

Table 2 Smear positivity versus cavitation results matrix

\begin{tabular}{llll}
\hline & \multicolumn{2}{l}{ Cavitary TB } & Total \\
\cline { 2 - 3 } & Yes (\%) & No (\%) & \\
\hline AFB result & & $31(13.7)$ & $\mathbf{1 7 7}(\mathbf{4 2 . 0 )}$ \\
Positive & $146(75.3)$ & $196(86.3)$ & $\mathbf{2 4 4}(\mathbf{5 8 . 0 )}$ \\
Negative & $48(24.7)$ & $\mathbf{2 2 7}$ & $\mathbf{4 2 1}$ \\
Total & $\mathbf{1 9 4}$ &
\end{tabular}

Key: The percentages indicate the proportions of smear positive and negative patients among Cavitary and non-Cavitary cases 
Table 3 Factors Associated with Pulmonary cavitation of TB patients in Somali region, Ethiopia, December 2017 to October 2018

\begin{tabular}{|c|c|c|c|c|c|c|}
\hline Characteristics $(n=434)$ & Total PTB cases $n(\%)$ & Cavitary TB n (\%) & $P$-value & PR $(95 \% \mathrm{Cl})$ & $P$-value & APR $(95 \% \mathrm{Cl})$ \\
\hline \multicolumn{7}{|l|}{ Sex } \\
\hline Female & $161(37.1)$ & $70(43.5)$ & $0.49^{*}$ & 1 & - & - \\
\hline Male & $273(62.9)$ & $128(46.9)$ & & $1.1(0.9,1.3)$ & & \\
\hline \multicolumn{7}{|l|}{ Age } \\
\hline 15 to 35 & $251(57.8)$ & $125(49.8)$ & 0.04 & $1.3(1.01,1.6)$ & 0.04 & $1.3(1.01,1.6)$ \\
\hline $36+$ & $183(42.2)$ & $73(39.9)$ & & 1 & & 1 \\
\hline \multicolumn{7}{|l|}{ Livelihood } \\
\hline Pastoralism & $202(46.5)$ & $96(47.5)$ & $0.45^{*}$ & $1.1(0.9,1.3)$ & - & - \\
\hline Non-pastoralism & $232(53.5)$ & $102(44.0)$ & & 1 & & \\
\hline \multicolumn{7}{|l|}{ Smoking } \\
\hline Ever smoker & $45(10.4)$ & $23(51.1)$ & $0.40^{*}$ & $1.1(0.8,1.5)$ & - & - \\
\hline Never smoker & $389(89.6)$ & $175(45.0)$ & & 1 & & \\
\hline \multicolumn{7}{|l|}{ BCG scar } \\
\hline Yes & $52(12.0)$ & $26(50.0)$ & $0.48^{*}$ & $1.1(0.8,1.5)$ & - & - \\
\hline No & $382(88.0)$ & $172(45.0)$ & & 1 & & \\
\hline \multicolumn{7}{|c|}{ Chronic diseases (HTP/CHD/CRD) } \\
\hline Yes & $20(4.6)$ & $12(60)$ & 0.13 & $1.3(0.9,1.9)$ & 0.006 & $1.8(1.2,2.6)$ \\
\hline No & $414(95.4)$ & $186(44.9)$ & & 1 & & 1 \\
\hline \multicolumn{7}{|l|}{$\operatorname{MUAC}_{\text {female }}(n=161)$} \\
\hline $\operatorname{Low}(\leq 23 \mathrm{~cm})$ & $93(57.8)$ & $51(54.8)$ & 0.002 & $2.0(1.3,3.0)$ & 0.01 & $1.8(1.13,2.8)$ \\
\hline High $(>23 \mathrm{~cm})$ & $68(42.2)$ & $19(27.9)$ & & 1 & & 1 \\
\hline \multicolumn{7}{|l|}{$\operatorname{MUAC}_{\text {male }}(n=273)$} \\
\hline $\operatorname{Low}(\leq 23 \mathrm{~cm})$ & $154(56.4)$ & $74(48.1)$ & $0.63^{*}$ & $1.1(0.8,1.4)$ & - & - \\
\hline High (> $23 \mathrm{~cm})$ & $119(43.6)$ & $54(45.4)$ & & 1 & & \\
\hline \multicolumn{7}{|l|}{ BMl } \\
\hline Low $(<18.5)$ & $304(70.0)$ & $149(49.0)$ & 0.04 & $1.3(1.01,1.7)$ & 0.23 & $1.2(0.9,1.5)$ \\
\hline High $(\geq 18.5)$ & $130(30.0)$ & $49(37.7)$ & & 1 & & 1 \\
\hline \multicolumn{7}{|l|}{ Prior history of TB } \\
\hline Yes & $65(15.0)$ & $31(47.7)$ & $0.71^{*}$ & $1.1(0.8,1.4)$ & - & - \\
\hline No & $369(85.0)$ & $167(45.3)$ & & 1 & & \\
\hline \multicolumn{7}{|l|}{ Delay in diagnosis (days) } \\
\hline 30 or less & $90(20.7)$ & $20(22.2)$ & 1 & 1 & - & 1 \\
\hline 31 to 49 & $138(31.8)$ & $58(42.0)$ & 0.004 & $1.9(1.2,2.9)$ & 0.006 & $1.8(1.2,2.8)$ \\
\hline 50 to 70 & $98(22.6)$ & $54(55.1)$ & $<0.001$ & $2.5(1.6,3.8)$ & $<0.001$ & $2.4(1.6,3.7)$ \\
\hline 71 or more & $108(24.9)$ & $66(61.1)$ & $<0.001$ & $2.8(1.8,4.2)$ & $<0.001$ & $2.7(1.8,4.1)$ \\
\hline
\end{tabular}

Key: MUAC and BMI Cutoffs were $23 \mathrm{~cm}$ and $18.5 \mathrm{Kg} / \mathrm{M} 2$; Delay categorized at 25th, 50th and 75th quartile days; 1 indicates reference category; ${ }^{*}$ indicates the variable not included in multivariable regression analysis; $B C G$ Bacillus Calmette-Guerin, PR Prevalence ratio, APR Adjusted prevalence ratio, $H T P / C H D / C R D$ Hypertension/Chronic Heart Disease/Chronic Renal Disease

patients in the study area received medical care after the disease gets severe and hazardous.

Our study reveals that the elevated levels of cavitation and smear positivity were attributed to delays in diagnosis and treatment. The threshold delay (43 days) that optimizes cavitation was below the median delay (49 days), or $60 \%$ of patients had diagnosis delay longer than the threshold delay. Extreme delay does not only increase infectiousness as figured out here or elsewhere [12, 13], but it also prolongs the contagious period and contact time between patients and contacts [16]. The majority of infectious patients (90\% of cavitary and $84 \%$ of smear positive) delayed longer than a month with average six-plus household members. Household transmission could be, therefore, higher in pastoral communities bearing in mind their 
Table 4 Factors Associated with Sputum Smear positivity of TB patients in Somali region, Ethiopia, December 2017 to October 2018

\begin{tabular}{|c|c|c|c|c|c|c|}
\hline Characteristics $(n=434)$ & Total PTB cases $n(\%)$ & Smear positive TB n (\%) & $P$-value & PR $(95 \%$ Cl) & $P$-value & APR $(95 \% \mathrm{Cl})$ \\
\hline \multicolumn{7}{|l|}{ Sex } \\
\hline Female & $157(37.3)$ & $58(36.9)$ & 0.11 & 1 & 0.17 & 1 \\
\hline Male & $264(62.7)$ & $119(45.1)$ & & $1.2(0.9,1.5)$ & & $1.2(0.9,1.5)$ \\
\hline \multicolumn{7}{|l|}{ Age } \\
\hline 15 to 35 & $245(58.2)$ & $119(48.6)$ & 0.002 & $1.5(1.2,1.9)$ & 0.007 & $1.4(1.1,1.8)$ \\
\hline $36+$ & $176(41.8)$ & $58(33.0)$ & & 1 & & 1 \\
\hline \multicolumn{7}{|l|}{ Livelihood } \\
\hline Pastoralism & $194(46.1)$ & $81(41.8)$ & $0.91^{*}$ & $0.98(0.79,1.24)$ & - & - \\
\hline Non-pastoralism & $227(53.9)$ & $96(42.3)$ & & 1 & & \\
\hline \multicolumn{7}{|l|}{ Smoking } \\
\hline Ever smoker & $43(10.2)$ & $22(51.2)$ & 0.17 & $1.2(0.9,1.7)$ & 0.28 & $1.2(0.8,1.6)$ \\
\hline Never smoker & $378(89.8)$ & $155(41.0)$ & & 1 & & 1 \\
\hline \multicolumn{7}{|l|}{ BCG scar } \\
\hline Yes & $52(12.4)$ & $23(44.2)$ & $0.61^{*}$ & $1.01(0.7,1.4)$ & - & - \\
\hline No & $369(87.6)$ & $154(41.7)$ & & 1 & & \\
\hline \multicolumn{7}{|c|}{ Chronic diseases (HTP/CHD/CRD) } \\
\hline Yes & $20(4.8)$ & $8(40.0)$ & $0.85^{*}$ & $0.95(0.5,1.6)$ & - & - \\
\hline No & $401(95.2)$ & $169(42.1)$ & & 1 & & \\
\hline \multicolumn{7}{|l|}{ MUAC } \\
\hline $\operatorname{Low}(\leq 23 \mathrm{~cm})$ & $235(55.8)$ & $119(50.6)$ & $<0.001$ & $1.6(1.3,2.1)$ & 0.003 & $1.5(1.2,1.9)$ \\
\hline High $(>23 \mathrm{~cm})$ & $186(44.2)$ & $58(31.2)$ & & 1 & & 1 \\
\hline \multicolumn{7}{|l|}{ BMI } \\
\hline Low $(<18.5)$ & $294(69.8)$ & $135(45.9)$ & 0.02 & $1.4(1.1,1.8)$ & 0.04 & $1.3(1.01,1.7)$ \\
\hline High ( $\geq 18.5)$ & $127(30.2)$ & $42(33.1)$ & & 1 & & 1 \\
\hline \multicolumn{7}{|l|}{ Prior history of TB } \\
\hline Yes & $65(15.4)$ & $22(33.8)$ & 0.17 & $0.8(0.5,1.1)$ & 0.25 & $0.8(0.6,1.2)$ \\
\hline No & $356(84.6)$ & $155(43.5)$ & & 1 & & 1 \\
\hline \multicolumn{7}{|l|}{ Delay in diagnosis (days) } \\
\hline 49 or less & $222(52.7)$ & $83(37.4)$ & 0.04 & 1 & 0.02 & 1 \\
\hline 50 or more & 199 (47.3) & $94(47.2)$ & & $1.3(1.01,1.6)$ & & $1.3(1.1,1.6)$ \\
\hline
\end{tabular}

Key: MUAC and BMI Cutoffs were $23 \mathrm{~cm}$ and $18.5 \mathrm{Kg} / \mathrm{M}^{2}$; Delay categorized at median day; 1 indicates reference category; ${ }^{*}$ indicates the variable not included in multivariable regression analysis; BCG Bacillus Calmette-Guerin, AFB Acid-Fast Bacilli, PR Prevalence ratio, APR Adjusted prevalence ratio, $H T P / C H D / C R D$ Hypertension/Chronic Heart Disease/Chronic Renal Disease

petite transitory huts with closed indoor spaces. Moreover, the high delays could threaten treatment outcomes. The high cavitation due to delay could result in treatment failure/relapse, emergence of drug resistance and permanent lung impairments [28]. Recent findings call for extended treatment of cavitary TB with a combination of new drugs and strategies [34], yet no special strategy is currently in place in Ethiopia. Hence, the effects of delay on treatment outcomes and household transmission should be evaluated in such areas.
In addition to delay, cavitation and smear positivity were also associated with younger ( $\leq 35$ years), undernutrition and the presence of chronic diseases comorbidity after adjusting for potential confounders. The risk of cavitation is likely higher in younger and immune competent patients $[35,36]$. This is because concomitant and weakening physical conditions blunt inflammatory responses in older people [37]. The association of cavitation and smear positivity with undernutrition could be either way; undernutrition led to immune-deficiency and enhanced disease progression [38, 39], or the disease itself 


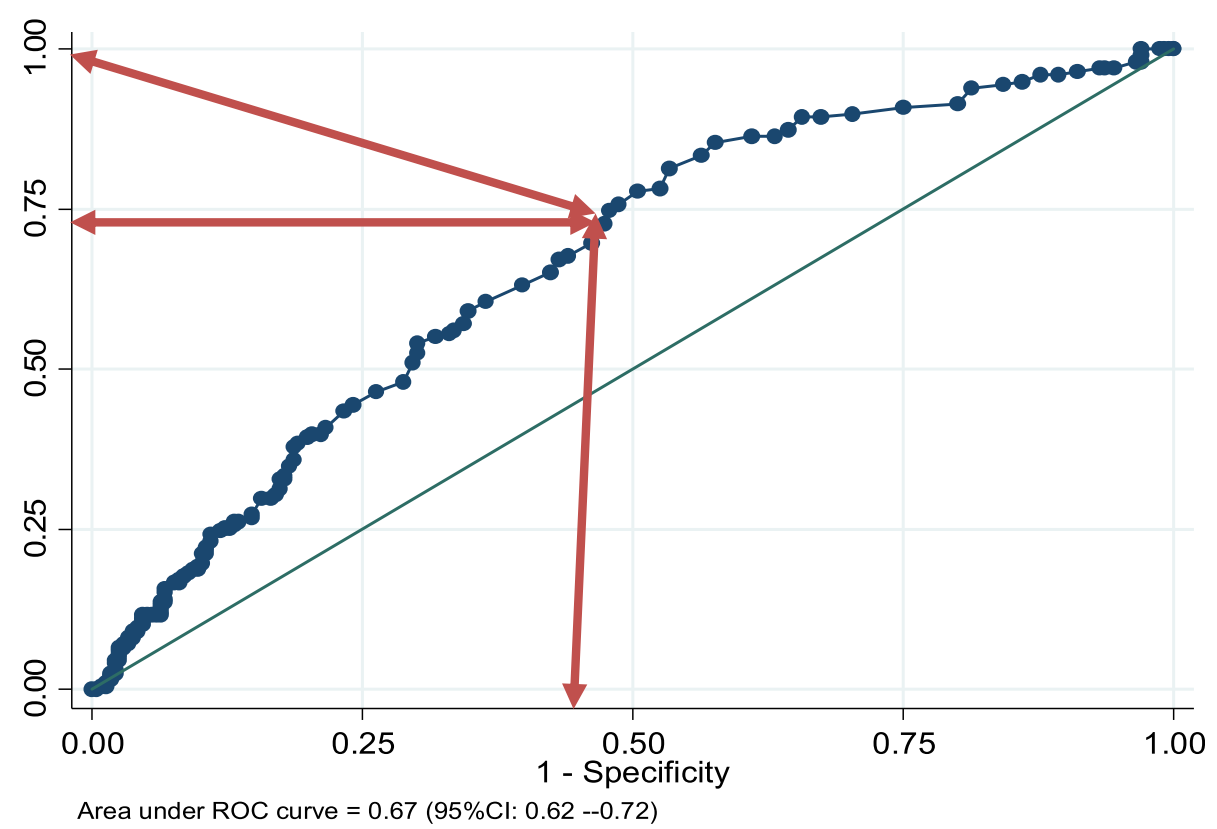

Fig. 2 ROC curve (horizontal = l-specificity, vertical = sensitivity) illustrating diagnosis delay as predictor of pulmonary cavitation

led to under-nutrition [40]. Unlike this study, other studies revealed diabetes, smoking and low income [41-43] as factors associated with cavitation and smear positivity. The reason why these were not witnessed in the current study might be due to the small number of cases that cohabit these factors.
However, this study is subjected to certain limitation. The reduced sensitivity of Chest X-ray, and salivary sputum and missed smears might underestimate cavitation, and smear positivity, respectively. Recall bias might influence the precision of delay. Moreover, the proportion of pastoralists seems less represented due to the reduced

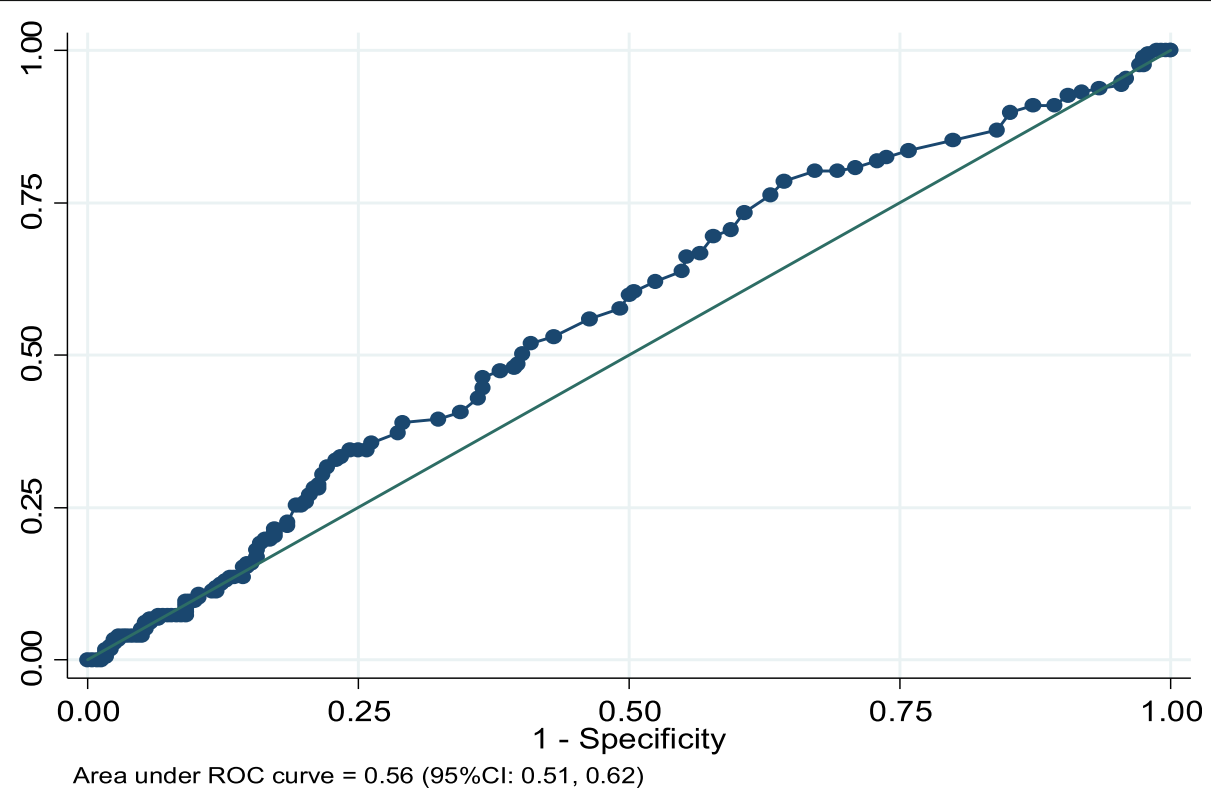

Fig. 3 ROC curve (horizontal = l-specificity, vertical = sensitivity) illustrating diagnosis delay as predictor of smear positivity 
case notification that was observed during dry seasons when they move for pasture and water.

\section{Conclusion}

This study highlights delay in diagnosis and treatment remained high and substantially increased infectiousness of patients with pulmonary tuberculosis in pastoral settings in Ethiopia. Delay of 43 days looks the threshold delay at which risk of cavitation increases significantly, but around two-third of patients obtained diagnosis after this cutoff point. The high levels of cavitation and smear positivity because of excessive delays suggests a threat of high disease transmission and adverse treatment outcomes in the pastoral area. Thus, delay in diagnosis and treatment of TB cases should be targeted for effective control of the disease and prevent the risk of transmission in the pastoralist areas of the country. Strategies that suit socio-cultural needs of pastoralists such as mobile screening services need to be adapted to ensure early detection and treatment of TB.

\section{Supplementary information}

Supplementary information accompanies this paper at https://doi.org/10. 1186/s12890-019-0971-y.

Additional file 1. Questionnaire

\section{Abbreviations}

AFB: Acid Fast Bacilli; AHRI: Armauer Hansen Research Institute; APR: Adjusted Prevalence Ratio; AUC: Area Under the Curve; BCG: Bacillus Calmette-Guerin BMI: Body Mass Index; Cl: Confidence Interval; CM: Centimeters; DOTS: Directly Observed Therapy-Short Course; FMOH: Federal Ministry of Health; HIV: Human Immunodeficiency Virus; IQR: Inter-Quartile Range; Kg: Kilogram; M: Meter; MDR: Multi-Drug Resistant; MTB: Mycobacterium tuberculosis; MUAC: Mid-Upper Arm Circumference; NTP: National TB Control Program; PR: Prevalence Ratio; PTB: Pulmonary Tuberculosis; ROC: Receiver operating characteristic; SRS: Somali Regional State; TB: Tuberculosis; WHO: World Health Organization

\section{Acknowledgements}

We are very grateful to Haramaya University and AHRI for protocol evaluation and ethical approval. Our special gratitude goes to Somali Regional Health Bureau and the respective study facilities for their support during data collection including transport and logistic support, and permitting TB care providers' engagement in data collection. TB care providers, radiography and laboratory technologists deserve the utmost gratitude for their vigilant effort in data collection process. Our sincere gratefulness also goes to Dr. Solomon Bishaw, Radiologist at Hiwot Fana Hospital, for his support during re-examination of sampled X-ray films, and Manendante Mulugeta (PhD in TEFL) for his language editing. Permission was obtained to use full names.

\section{Authors' contributions}

FG conceived this research, developed draft protocol, coordinated fieldwork, led data analysis, and wrote draft manuscript. MD enriched the conception, revised and approved all drafts of the protocol and manuscript. AW directed data analysis, and revised and approved all drafts of protocol and manuscript. TG, RT and BS directed the fieldwork, and revised and approved all drafts of the protocol and manuscript. GA developed AFB examination procedures, co-facilitated fieldwork and led AFB examinations, and revised and approved final draft of the manuscript. MG led Chest X-ray imaging, examinations, and revised and approved final draft of the manuscript. All authors read and approved the final manuscript version sent for publication.

\section{Funding}

This study was funded by the Swiss Agency for Development and Cooperation (SDC) in the frame of Jigjiga One Health Initiative $(\mathrm{JOHI})$ and Jigjiga University. Swill Tropical and Public Health Institute also provided logistic support. Funding bodies had no role in the design of the study and collection, analysis, and interpretation of data and in writing the manuscript.

\section{Availability of data and materials}

The dataset supporting the conclusions of this article is included within the article. The collected data contain confidential information, and consent has not been obtained for public sharing of raw data with identifiers. However, the datasets used and/or analyzed are available at the hands of the corresponding author and can be shared upon reasonable requests.

\section{Ethics approval and consent to participate}

Ethical approval was obtained from Institutional Health Research Ethics Review Committee (IHRERC) of Haramaya University, College of Health and Medical Sciences (Ref.No: IHRERC/009/2016), and AHRI/ALERT Ethical Review Committee (Ref.No: P001/17). Written consent was obtained upon provision of information for participants and parents/guardians of 15-17 years old participants as well as assent from 15 to 17 years old participants.

Participation was self-determined and discontinuation was guaranteed.

\section{Consent for publication}

Not applicable.

\section{Competing interests}

The authors declare that they have no competing interests.

\section{Author details}

${ }^{1}$ College of Medicine and Health Sciences, Jigjiga University, Jijiga, Ethiopia. ${ }^{2}$ Addis Continental Institute of Public Health, Addis Ababa, Ethiopia. ${ }^{3}$ School of Public Health, Addis Ababa University, Addis Ababa, Ethiopia. ${ }^{4}$ School of Public Health, Haramaya University, Dire Dawa, Ethiopia. ${ }^{5}$ Armauer Hansen Research Institute, Addis Ababa, Ethiopia. ${ }^{6}$ Swiss Tropical and Public Health Institute, Basel, Switzerland. ${ }^{7}$ University of Basel, Basel, Switzerland. ${ }^{8}$ Karamara Referral Hospital, Jijiga, Ethiopia.

Received: 21 September 2019 Accepted: 21 October 2019

Published online: 06 November 2019

\section{References}

1. WHO. Global tuberculosis report 2018: World Health Organization; 2018.

2. Kebede AH, Alebachew TZF, Lemma E, Abebe A, Agonafir M, et al. The first population-based national tuberculosis prevalence survey in Ethiopia, 20102011. IJTLD. 2014;18(6):635-9. https://doi.org/10.5588/ijtld.5513.0417.

3. Lönnroth K, Raviglione M. The WHO's new end TB strategy in the post-2015 era of the sustainable development goals. Trans R Soc Trop Med Hyg. 2016; 110(3):148-50

4. FMOH. National Guidelines for TB, DR-TB and leprosy in Ethiopia. 6th ed. Addis Ababa: Ethiopia FMOHo; 2017.

5. Ho J, Fox GJ, Marais BJ. Passive case finding for tuberculosis is not enough. Int J Mycobacteriol. 2016;5(4):374-8.

6. Tadesse T, Demissie M, Berhane Y, Kebede Y, Abebe M. Two-thirds of smear-positive tuberculosis cases in the community were undiagnosed in Northwest Ethiopia: population based cross-sectional study. PLoS One. 2011 6(12):e28258.

7. Hamusse S, Demissie M, Teshome D, Hassen MS, Lindtjorn B. Prevalence and incidence of smear-positive pulmonary tuberculosis in the Hetosa District of Arsi zone, Oromia regional state of Central Ethiopia. BMC Infect Dis. 2017;17(1):214

8. RHB. Regional health services coverage for the year 2010 Ethiopian calender. Jigjiga: Regional Health Bureau; 2019

9. Getnet F, Demissie M, Assefa N, Mengistie B, Worku A. Delay in diagnosis of pulmonary tuberculosis in low-and middle-income settings: systematic review and meta-analysis. BMC Pulm Med. 2017;17(1):202.

10. Li Y, Ehiri J, Tang S, Li D, Bian Y, Lin H, et al. Factors associated with patient, and diagnostic delays in Chinese TB patients: a systematic review and metaanalysis. BMC Med. 2013;11:156 http://www.biomedcentral.com/1741-7015/1 $711 / 1156$. 
11. Gele AA, Bjune G, Abebe F. Pastoralism and delay in diagnosis of TB in Ethiopia. BMC Public Health. 2009;9:5-5.

12. Cheng S, Chen W, Yang Y, Chu P, Liu X, Zhao M, et al. Effect of diagnostic and treatment delay on the risk of tuberculosis transmission in Shenzhen, China: an observational cohort study, 1993-2010. PLoS One. 2013;8(6):e67516.

13. Virenfeldt J, Rudolf F, Camara C, Furtado A, Gomes V, Aaby P, et al. Treatment delay affects clinical severity of tuberculosis: a longitudinal cohort study. BMJ Open. 2014;4(6):e004818.

14. Squeglia F, Ruggiero A, Berisio R. Collagen degradation in tuberculosis pathogenesis: the biochemical consequences of hosting an undesired guest. Biochem J. 2018;475(19):3123-40.

15. Ravimohan S, Kornfeld H, Weissman D, Bisson GP. Tuberculosis and lung damage: from epidemiology to pathophysiology. Eur Respir Rev. 2018; 27(147). https://doi.org/10.1183/16000617.0077-2017.

16. Mathema B, Andrews JR, Cohen T, Borgdorff MW, Behr M, Glynn JR, et al. Drivers of tuberculosis transmission. J Infect Dis. 2017;216(suppl_6):S644-s653.

17. CSA. Population projection of Ethiopia for all regions: at Wereda level from 2014-2017. Addis Ababa: Central Statistical Agency of Federal Democratic Republic of Ethiopia; 2013.

18. Gadkowski LB, Stout JE. Cavitary pulmonary disease. Clin Microbiol Rev. 2008;21(2):305-33.

19. Hunter RL. Pathology of post primary tuberculosis of the lung: an illustrated critical review. Tuberculosis (Edinb). 2011;91(6):497-509.

20. Lin X, Chongsuvivatwong V, Lin L, Geater A, Lijuan R. Dose-response relationship between treatment delay of smear-positive tuberculosis patients and intra-household transmission: a cross-sectional study. Trans $\mathrm{R}$ Soc Trop Med Hyg. 2008;102(8):797-804.

21. WHO. Diagnostic and treatment delay in tuberculosis. In: An in-depth analysis of the health-seeking behaviour of patients and health system response in seven countries of the eastern Mediterranean region; 2006. WHO-EM/TDR/009/E/10.06/1000.

22. Hussen A, Biadgilign S, Tessema F, Mohammed S, Deribe K, Deribew A. Treatment delay among pulmonary tuberculosis patients in pastoralist communities in bale zone, Southeast Ethiopia. BMC Res Notes. 2012:5:320.

23. Mesfin MM, Newell JN, Walley JD, Gessessew A, Madeley RJ. Delayed consultation among pulmonary tuberculosis patients: a cross sectional study of 10 DOTS districts of Ethiopia. BMC Public Health. 2009;9:53.

24. Palaci M, Dietze R, Hadad DJ, Ribeiro FKC, Peres RL, Vinhas SA, et al. Cavitary disease and quantitative sputum bacillary load in cases of pulmonary tuberculosis. J Clin Microbiol. 2007:45(12):4064-6.

25. Tang AM, Chung M, Dong K, Wanke C, Bahwere P, Bose K, et al. Determining a global mid-upper arm circumference cutoff to assess underweight in adults (men and nonpregnant women); 2017.

26. Curvo-Semedo L, Teixeira L, Caseiro-Alves F. Tuberculosis of the chest. Eur J Radiol. 2005;55(2):158-72.

27. Nachiappan AC, Rahbar K, Shi X, Guy ES, Mortani Barbosa EJ Jr, Shroff GS, et al. Pulmonary tuberculosis: role of radiology in diagnosis and management. Radiographics. 2017;37(1):52-72.

28. Huang Q, Yin Y, Kuai S, Yan Y, Liu J, Zhang Y, et al. The value of initial cavitation to predict re-treatment with pulmonary tuberculosis. Eur J Med Res. 2016:21(1):20

29. Zhang L, Pang Y, Yu X, Wang Y, Lu J, Gao M, et al. Risk factors for pulmonary cavitation in tuberculosis patients from China. Emerg Microbes Infect. 2016;5(1):1-11.

30. Manzano KR. Prevalence and risk factors of Cavitary lung lesions in a metropolitan hospital at san Juan Puerto Rico. Chest Infect. 2015;148(4):143A.

31. Belay M, Bjune G, Ameni G, Abebe F. Diagnostic and treatment delay among tuberculosis patients in Afar region, Ethiopia: a cross-sectional study. BMC Public Health. 2012;12:369.

32. Gebreegziabher SB, Bjune GA, Yimer SA. Patients' and health system's delays in the diagnosis and treatment of new pulmonary tuberculosis patients in west Gojjam zone, Northwest Ethiopia: a cross-sectional study. BMC Infect Dis. 2016;16(1):673

33. Seid A, Metaferia Y. Factors associated with treatment delay among newly diagnosed tuberculosis patients in Dessie city and surroundings, northern Central Ethiopia: a cross-sectional study. BMC Public Health. 2018;18(1):931

34. Saeed W. Cavitating pulmonary tuberculosis: a global challenge. Clin Med (Lond). 2012:12(1):40-1.

35. Perez-Guzman C, Torres-Cruz A, Villarreal-Velarde H, Vargas MH. Progressive age-related changes in pulmonary tuberculosis images and the effect of diabetes. Am J Respir Crit Care Med. 2000;162(5):1738-40.
36. Mathur M, Badhan RK, Kumari S, Kaur N, Gupta S. Radiological manifestations of pulmonary tuberculosis - a comparative study between immunocompromised and immunocompetent patients. J Clin Diagn Res. 2017:11(9):Tc06-tc09.

37. Perez-Guzman C, Vargas MH, Torres-Cruz A, Villarreal-Velarde H. Does aging modify pulmonary tuberculosis?: a meta-analytical review. Chest. 1999: 116(4):961-7.

38. Chandrasekaran P, Saravanan N, Bethunaickan R, Tripathy S. Malnutrition: modulator of immune responses in tuberculosis. Front Immunol. 2017:8:1316

39. Anuradha R, Munisankar S, Bhootra Y, Kumar NP, Dolla C, Kumaran P, et al. Coexistent malnutrition is associated with perturbations in systemic and antigen-specific cytokine responses in latent tuberculosis infection. Clin Vaccine Immunol. 2016;23(4):339-45.

40. Kant S, Gupta H, Ahluwalia S. Significance of nutrition in pulmonary tuberculosis. Crit Rev Food Sci Nutr. 2015:55(7):955-63.

41. de Albuquerque MF, Albuquerque SC, Campelo AR, Cruz M, de Souza WV, Ximenes RA, et al. Radiographic features of pulmonary tuberculosis in patients infected by HIV: is there an objective indicator of co-infection? Rev Soc Bras Med Trop. 2001;34(4):369-72.

42. Alkabab YM, Enani MA, Indarkiri NY, Heysell SK. Performance of computed tomography versus chest radiography in patients with pulmonary tuberculosis with and without diabetes at a tertiary hospital in Riyadh, Saudi Arabia. Infect Drug Resist. 2018;11:37-43.

43. Nijenbandring de Boer R, Oliveira e Souza Filho JB, Cobelens F, Ramalho Dde P, Campino Miranda PF, Logo K, et al. Delayed culture conversion due to cigarette smoking in active pulmonary tuberculosis patients. Tuberculosis (Edinb). 2014;94(1):87-91.

\section{Publisher's Note}

Springer Nature remains neutral with regard to jurisdictional claims in published maps and institutional affiliations.

Ready to submit your research? Choose BMC and benefit from:

- fast, convenient online submission

- thorough peer review by experienced researchers in your field

- rapid publication on acceptance

- support for research data, including large and complex data types

- gold Open Access which fosters wider collaboration and increased citations

- maximum visibility for your research: over $100 \mathrm{M}$ website views per year

At $\mathrm{BMC}$, research is always in progress.

Learn more biomedcentral.com/submissions 